\title{
Acquired Rifamycin Resistance with Twice-Weekly Treatment of HiV-related Tuberculosis
}

\author{
William Burman, Debra Benator, Andrew Vernon, Awal Khan, Brenda Jones, Claudia Silva, Chris Lahart, \\ Stephen Weis, Barbara King, Bonita Mangura, Marc Weiner, Wafaa El-Sadr, and the Tuberculosis Trials \\ Consortium
}

Denver Public Health; University of Colorado Health Sciences Center, Denver, Colorado; Veterans Affairs Medical Center of Washington, DC; George Washington University Medical Center, Washington, DC; Centers for Disease Control and Prevention, Atlanta, Georgia; Los Angeles County-University of Southern California Medical Center, Los Angeles, California; Baylor College of Medicine, Houston; Tarrant County Public Health Department; University of North Texas Health Sciences Center, Fort Worth; University of Texas Health Science Center; South Texas Veterans Health Care System, San Antonio, Texas; University of Medicine and Dentistry of New Jersey-New Jersey Medical School National Tuberculosis Center, Newark, New Jersey; Harlem Hospital Center; and Columbia University College of Physicians and Surgeons, New York, New York

\begin{abstract}
Rationale: Rifabutin was recommended in place of rifampin during treatment of HIV-related tuberculosis (TB) to facilitate concomitant potent antiretroviral therapy, but this approach has not been evaluated in a prospective study.

Objective: To evaluate the activity of intermittent rifabutin-based therapy.

Methods: Patients with culture-confirmed TB were treated under direct supervision with $\mathbf{2}$ mo of rifabutin, isoniazid, pyrazinamide, and ethambutol (given daily, thrice-weekly, or twice-weekly per the local tuberculosis control program), followed by 4 mo of twiceweekly rifabutin plus isoniazid.

Measurements: Culture-positive treatment failure or relapse.

Main Results: A total of 169 eligible patients were enrolled. Most had advanced HIV disease; the median CD4 cell count and HIVRNA level were 90 cells $/ \mathrm{mm}^{3}$ (interquartile range, 35-175) and 5.3 $\log _{10}$ copies/ml (interquartile range, 4.8-5.7), respectively. Nine $(5.3 \%)$ patients had culture-positive treatment failure $(n=3)$ or relapse $(n=6)$. Eight of these nine $(89 \%)$ cases had isolates with acquired rifamycin resistance. Treatment failure or relapse was associated with baseline CD4 lymphocyte count, being 12.3\% (9/73; 95\% confidence interval, 6.5-22.0\%) among patients with CD4 < 100 cells $/ \mathrm{mm}^{3}$ versus $0 \%(0 / 65 ; 95 \%$ confidence interval, $0.0-4.5 \%)$ among those with higher CD4 lymphocyte counts $(p<0.01)$. One hundred thirty-seven $(81 \%)$ patients received antiretroviral therapy during TB treatment. Adverse events were common, but only two patients (1\%) permanently discontinued study drugs.

Conclusions: Intermittent rifabutin-based therapy for HIV-related TB was well tolerated, but there was a high risk of treatment failure or relapse with acquired rifamycin resistance among patients with low CD4 lymphocyte counts.
\end{abstract}

Keywords: antiretroviral therapy; HIV; rifabutin; rifamycin resistance; tuberculosis

In many parts of the world, tuberculosis (TB) is the most common opportunistic infection among persons with HIV disease (1-3). TB complicating HIV infection is associated with a 20 to $50 \%$ risk of death within the first year after diagnosis (4-6). Death soon after the diagnosis may be due to TB, but most deaths among patients with HIV-related TB are due to other

(Received in original form March 16, 2005; accepted in final form August 16, 2005) Supported by the U.S. Centers for Disease Control and Prevention.

Correspondence and requests for reprints should be addressed to William Burman, M.D., Denver Public Health, 605 Bannock Street, Denver, CO 80204 . E-mail: bburman@dhha.org

Am J Respir Crit Care Med Vol 173. pp 350-356, 2006

Originally Published in Press as DOI: 10.1164/rccm.200503-4170C on August 18, 2005 Internet address: www.atsjournals.org complications of HIV $(4,5)$. Antiretroviral therapy markedly improves survival among patients with advanced HIV disease $(7,8)$ and may improve survival with HIV-related TB (9). However, the use of combination antiretroviral therapy during treatment of TB is complicated by overlapping side-effect profiles of anti-TB and antiretroviral drugs, complex drug-drug interactions between the rifamycins and many antiretroviral drugs, and immune reconstitution reactions after initiation of antiretroviral therapy (10).

Rifampin markedly decreases serum concentrations of the HIV-1 protease inhibitors (11), and has substantial effects on concentrations of two of the available nonnucleoside reversetranscriptase inhibitors (delavirdine and nevirapine) (12), thus limiting the choice of antiretroviral drugs. An alternate rifamycin antibiotic, rifabutin, has much less effect on serum concentrations of these antiretroviral drugs (12) and appears to be as potent as rifampin for the treatment of TB (13-15). Therefore, rifabutin-based therapy was recommended by the Centers for Disease Control and Prevention (CDC) as a way of avoiding serious drug-drug interactions and allowing use of potent antiretroviral therapy during TB treatment (16). However, there is relatively little published clinical experience with rifabutin-based therapy for HIV-related TB (15). The Tuberculosis Trials Consortium evaluated the efficacy and tolerability of a standard rifabutin-based regimen for treatment of HIV-related TB (TBTC Study 23). Preliminary results of this study were reported in the form of an abstract (17) and a special "Note to Readers" of the Morbidity and Mortality Weekly Report (18).

\section{METHODS}

Patients 18 yr or older at participating sites in the United States and Canada with confirmed HIV infection and suspected or confirmed TB were eligible for enrollment. Patients were excluded if they had received treatment for active or latent TB within the previous 6 mo, were pregnant or breast-feeding, or if the initial mycobacterial cultures were negative or grew rifamycin-resistant Mycobacterium tuberculosis. The study was reviewed and approved by the institutional review boards of the CDC and each clinical site. All patients gave written, informed consent.

Patients could be enrolled at any time during the first 2 mo of TB treatment. Patients who enrolled before the completion of the intensive phase of therapy (the first $2 \mathrm{mo}$ ) received rifabutin, isoniazid, pyrazinamide, and ethambutol, given daily for the first $2 \mathrm{wk}$ and then either daily $(5 \mathrm{~d} / \mathrm{wk})$, thrice-weekly, or twice-weekly based on the preference of the local TB control program. After 2 mo, all patients were treated with rifabutin $(300 \mathrm{mg})$ plus isoniazid $(15 \mathrm{mg} / \mathrm{kg}$; maximum, $900 \mathrm{mg}$ ) given twice weekly. All TB treatment was given as directly observed therapy, defined as the ingestion of study medication under the observation of a member of the study team. Completion of study therapy was defined as observed ingestion of 36 twice-weekly continuation-phase 
doses, not by calendar time. The type and timing of initiation of antiretroviral therapy were not determined by the study protocol. Rifabutin doses were adjusted according to current guidelines if given with the HIV-1 protease inhibitors or efavirenz (19).

TB treatment duration was $6 \mathrm{mo}$, with a mandatory extension to 9 mo for patients with a positive culture or lack of a clinical response at 2 mo of treatment (defined as persistent fever or progressive weight loss, and increase in size of lymph nodes, abscesses, or other tuberculous lesions) (16). Patients having an isoniazid-resistant isolate or who were intolerant of isoniazid were treated with 9 mo of rifabutin, pyrazinamide, and ethambutol; those having a pyrazinamide-resistant isolate or who were intolerant of pyrazinamide were treated with 9 mo of rifabutin plus isoniazid.

CD4 lymphocyte count and HIV-RNA level (bDNA Bayer Versant 3.0; Bayer Corporation, Tarrytown, NY) were performed at enrollment, after 2 mo of TB therapy, at end of treatment, and every 6 mo thereafter. We attempted to obtain sputum specimens from all patients at $2 \mathrm{mo}$ of treatment, regardless of the presence or absence of clinically evident pulmonary involvement. Patients with pulmonary involvement had sputum cultures obtained monthly during therapy and then at 1.5, 3, $6,12,18$, and 24 mo after completing therapy. At all of these time points, patients who could not produce an expectorated sputum specimen underwent sputum induction. Mycobacterial cultures were performed using liquid plus solid media at certified local laboratories. Isolates obtained at diagnosis and at the time of treatment failure or relapse underwent confirmatory drug-susceptibility testing (using solid media and the proportion method), DNA fingerprinting $(20,21)$, and sequencing of the rpoB gene (22).

The primary endpoint of the study was culture-confirmed treatment failure (positive culture during treatment, at or after Month 4) or relapse (positive culture after completing treatment). The planned sample size was 215 patients, allowing for $80 \%$ power to detect whether the rate of treatment failure plus relapse was higher than $10 \%$, twice that expected for treatment of drug-susceptible TB $(\leqslant 5 \%)$.

\section{Data Analysis}

All patients with culture-positive TB are included in the primary analysis; a second analysis was performed using patients who completed therapy as specified in the protocol. Categoric variables were compared using the two-tailed Fisher's exact test or $\chi^{2}$, and continuous variables with the Wilcoxon two-sample test. To identify factors associated with acquired rifamycin resistance, we compared patients having acquired rifamycin resistance to all other patients in the study. All patients in the study completed $8 \mathrm{wk}$ of four-drug therapy, but there were differences in the amount of that therapy that was administered twice-weekly. For the analysis of risk factors for acquired rifamycin resistance, patients who received four or more doses of their treatment as twice-weekly dosing during the first 2 mo were defined as having received twiceweekly therapy during induction phase. Because of the small number of cases of treatment failure or relapse it was not appropriate to perform multivariate analysis (23). However, among the 73 patients with a baseline CD4 cell count below 100 (which included all eight patients with acquired rifamycin resistance), we performed a stratified analysis of those factors associated with acquired rifamycin resistance in univariate analysis $(\mathrm{p}<0.20)$. Data analysis was performed using SAS version 8.0 (SAS Institute, Cary, NC) and EpiInfo, version 6.04d (CDC, Atlanta, GA).

\section{RESULTS}

A total of 180 patients were enrolled between December 1998 and March 2002 (Figure 1), 11 of whom were later excluded from the study (eight patients who did not have a positive mycobacterial culture and three patients who enrolled at sites that were closed soon after study initiation). The 169 remaining patients were used for the analyses that follow. Most patients were male and of Black or Hispanic race/ethnicity; $40 \%$ were born outside of the United States and Canada (Table 1). Nearly $45 \%$ of patients had extrapulmonary manifestations of TB; $22(13 \%)$ had only extrapulmonary involvement. Most patients had advanced HIV disease at the time of TB diagnosis; the median CD4 cell count and HIV-RNA level were 90 cells $/ \mathrm{mm}^{3}$ (interquartile

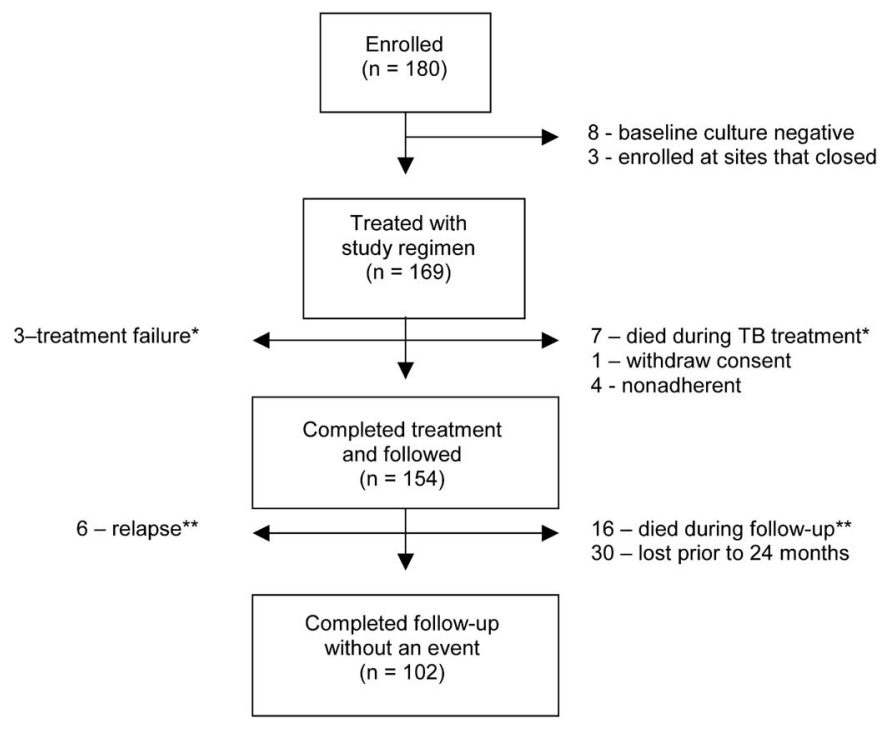

Figure 1. Patient flow in the study. ${ }^{*}$ One patient died after having failed; ${ }^{* *}$ one patient died after having relapsed (total deaths $=25$ ).

range, $35-175)$ and $5.3 \log _{10}$ copies/ml (interquartile range, $4.8-$ 5.7), respectively.

A data and safety monitoring board reviewed outcome data three times. In March 2002, the board recommended that enrollment be stopped because five cases of acquired rifamycin resistance had occurred among patients with treatment failure or relapse. At

TABLE 1. DEMOGRAPHIC AND CLINICAL CHARACTERISTICS OF PATIENTS

\begin{tabular}{|c|c|}
\hline Characteristic & $\begin{array}{l}\text { Patients Included } \\
\quad(n=169)\end{array}$ \\
\hline Median age, yr (IQR) & $40(34-46)$ \\
\hline Male/female, $\mathrm{n}$ & $133 / 36$ \\
\hline \multicolumn{2}{|l|}{ Race/ethnicity, n (\%) } \\
\hline Black & $84(50)$ \\
\hline Hispanic & $57(34)$ \\
\hline White, non-Hispanic & $19(11)$ \\
\hline Native American & $3(2)$ \\
\hline Asian/Pacific Islander & $6(4)$ \\
\hline \multicolumn{2}{|l|}{ Country of origin, $\mathrm{n}(\%)$} \\
\hline United States or Canada & $100(59)$ \\
\hline Other & $69(41)$ \\
\hline Homeless the within past $\mathrm{yr}, \mathrm{n}(\%)$ & $45(27)$ \\
\hline Injection drug use within the past $\mathrm{yr}, \mathrm{n}(\%)$ & $17(10)$ \\
\hline Alcohol abuse within the past $y r, \mathrm{n}(\%)$ & $57(34)$ \\
\hline \multicolumn{2}{|l|}{ Educational level, n (\%) } \\
\hline 8 th grade or less & $39(23)$ \\
\hline 9 th-11th grade & $48(29)$ \\
\hline Completed high school & $47(28)$ \\
\hline Some college & $34(20)$ \\
\hline \multicolumn{2}{|l|}{ Site of involvement, $\mathrm{n}(\%)$} \\
\hline Pulmonary & $93(55)$ \\
\hline Extrapulmonary & $22(13)$ \\
\hline Both & $54(32)$ \\
\hline Isoniazid resistance/isoniazid intolerance & $3 / 3$ \\
\hline Pyrazinamide resistance*/pyrazinamide intolerance & $5 / 1$ \\
\hline Median CD4 cell count at TB diagnosis (IQR) & $90(35-175)$ \\
\hline Median HIV RNA $\left(\log _{10}\right)$ at TB diagnosis (IQR) & $5.3(4.8-5.7)$ \\
\hline Prior AIDS-defining illness, n (\%) & $23(14)$ \\
\hline
\end{tabular}

Definition of abbreviations: IQR = interquartile range; TB = tuberculosis.

* Three of the five pyrazinamide-resistant isolates were identified as Mycobacterium bovis. 
the time enrollment was stopped, investigators were encouraged to use more frequent therapy (daily or thrice-weekly) and/or add medications such as ethambutol for patients having CD4 lymphocyte counts of less than 100 cells $/ \mathrm{mm}^{3}$ at study entry. Patients were monitored for $2 \mathrm{yr}$ after completing therapy.

\section{TB Treatment}

Of the 169 patients, 37 (22\%) enrolled before starting TB treatment, and were therefore treated with rifabutin from the outset. The other 132 patients were enrolled during the first 2 mo of therapy and had received a median of $33.5 \mathrm{~d}$ of rifampincontaining therapy (interquartile range, 16.5-56 d). During the first 2 mo of TB treatment, 76 (45\%) of patients received twiceweekly therapy. Most patients were treated for 6 mo. Treatment was extended to 9 mo for 16 patients (eight patients who were intolerant to or had an isolate resistant to isoniazid $[\mathrm{n}=5]$ or pyrazinamide $[\mathrm{n}=3$ ], four patients who had a positive sputum culture at 2 mo of treatment, two patients with lack of clinical response by $2 \mathrm{mo}$, and two patients because of provider preference). Thirty of 169 (17.8\%) were lost to follow-up before completing the study or reaching an endpoint (Figure 1). However, the lost-to-follow-up rate at 12 mo after completing therapy, the period of highest risk for recurrent TB, was 7.1\% (12 of 169).

\section{Treatment Failure and Relapse}

Nine patients had culture-positive treatment failure or relapse: three patients had treatment failure and six had relapse. Four of the six cases of relapse occurred within 6 mo of completing TB treatment. Overall, 5.3\% (9 of 169) of patients had treatment failure or relapse; by Kaplan-Meier analysis, $6.6 \%$ of patients had treatment failure or relapse by 2 yr after completing therapy. The rate of treatment failure or relapse was 3.0 per 100 patientyears of follow-up. Among the 142 patients who completed the study regimen as specified in the protocol, eight $(5.6 \%)$ had treatment failure or relapse (one patient with acquired rifamycin resistance had treatment failure after nonadherence). Treatment failure or relapse was associated with baseline CD4 lymphocyte count, being $12.3 \%$ (9/73; 95\% confidence interval, $6.5-22.0 \%)$ among patients with CD4 counts of less than 100 cells $/ \mathrm{mm}^{3}$ versus $0 \%(0 / 65 ; 95 \%$ confidence interval, $0.0-4.5 \%)$ among those with higher CD4 lymphocyte counts $(\mathrm{p}<0.01)$.

Eight of the nine isolates $(89 \%)$ obtained at the time of treatment failure or relapse had acquired rifamycin resistance (three cases of treatment failure and five cases of relapse). The median time from enrollment to acquired rifamycin resistance was $8.3 \mathrm{mo}$ (range, 4.7-24.5 mo). Multidrug resistance developed in one of these cases. A patient with an isolate having baseline pyrazinamide resistance developed recurrent suppurative cervical adenopathy at 5 mo of directly observed therapy. A percutaneous aspirate yielded an isolate with acquired rifamycin and isoniazid resistance. For all nine cases, the DNA fingerprint patterns of paired isolates at initial diagnosis and the time of treatment failure or relapse were identical. The rpoB gene sequences of the eight isolates having acquired rifamycin resistance had mutations previously associated with rifampin resistance (Ser531Leu [three cases], Gln513Leu [two cases], His526Tyr [two cases], His526Asp [one case]) (22). All patients with treatment failure or relapse responded to retreatment with a regimen active against rifamycin-resistant TB.

\section{Factors Associated with Rifamycin-resistant Treatment Failure or Relapse}

Patients with acquired rifamycin treatment failure or relapse had lower CD4 lymphocyte counts at the time of TB diagnosis than other patients (median CD4 lymphocyte count, 26 cells $/ \mathrm{mm}^{3}$ [interquartile range, 13-39] vs. 99 cells $/ \mathrm{mm}^{3}$ [interquartile range, 40-202]; $\mathrm{p}=0.001$, Wilcoxon). Birth outside the United States or Canada, the presence of extrapulmonary manifestations of TB, twice-weekly TB treatment during the first 2 mo of TB treatment, and lack of use of antiretroviral therapy during the first 2 mo of $\mathrm{TB}$ treatment were more common among cases with acquired rifamycin resistance (Table 2). Use of rifampin during intensive-phase therapy was not associated with risk of acquired rifamycin resistance. In a stratified analysis of those patients with baseline CD4 lymphocyte count of less than 100 cells $/ \mathrm{mm}^{3}$, lack of use of antiretroviral therapy during the first 2 mo of TB treatment remained of borderline statistical significance (Table 3; $\mathrm{p}<0.07$ ).

\section{Use of Antiretroviral Therapy}

Thirty-eight (22\%) patients were on antiretroviral therapy at the time of TB diagnosis, and 99 patients (59\%) started antiretroviral therapy during TB treatment. Therefore, $81 \%$ of patients $(137$ of 169) received antiretroviral therapy during TB treatment. Patients not started on antiretroviral therapy during TB treatment had higher CD4 lymphocyte counts than those who received antiretroviral therapy during TB treatment (median CD4 lymphocyte count among those who did not start antiretroviral therapy, 149 cells $/ \mathrm{mm}^{3}$ [interquartile range, 73-261] vs. 79 [interquartile range, $32-150] ; \mathrm{p}=0.02$ ). All patients who were treated with antiretroviral treatment received combination therapy; the most common regimens were two nucleoside analogs plus nelfinavir (47 patients) and two nucleoside analogs plus efavirenz (45 patients). CD4 lymphocyte counts rose substantially and HIV-RNA levels decreased during TB treatment (Figure 2). Twenty-six of the 169 patients $(15 \%)$ were diagnosed with immune reconstitution reactions, all of which occurred among patients receiving antiretroviral therapy (26 of 137, 19\%).

\section{Adverse Events}

Of 169 patients in the study, 25 (14.8\%) died and 25 (14.8\%) developed a new AIDS-defining condition (24). None of the deaths were due to TB; 17 were due to complications of HIV disease (AIDS wasting, five patients; opportunistic infection, nine patients; HIV-related malignancy, three patients), three to illicit drug overdose, and five to other causes (suicide, cardiovascular disease, liver failure, non-HIV-related cancer). Although adverse events were common during TB treatment, few were believed to be due to the TB treatment regimen, and only two patients permanently stopped study drugs due to an adverse event (Table 4).

\section{DISCUSSION}

This study is the largest prospective evaluation of a rifabutinbased TB treatment regimen in conjunction with use of potent antiretroviral therapy. The rate of treatment failure or relapse observed in the study was approximately $5 \%$, similar to that seen with standard rifampin-based TB therapy $(5,25)$, demonstrating the potency of rifabutin-based treatment for the treatment of HIV-related TB. The treatment regimen was also well tolerated, with only $1 \%$ of patients permanently discontinuing rifabutin due to an adverse event. However, eight of the nine patients who had treatment failure or relapse had isolates with acquired rifamycin resistance. Because rifamycins are the key to short-course TB treatment, the occurrence of acquired rifamycin resistance led to the early discontinuation of the study.

One of the most important benefits of directly observed therapy for TB is that it prevents selective drug taking, and thereby almost completely prevents acquired drug resistance $(14,26$, 27). However, this study demonstrates that this axiom of TB 
TABLE 2. UNIVARIATE ANALYSIS OF FACTORS ASSOCIATED WITH ACQUIRED RIFAMYCIN RESISTANCE

\begin{tabular}{|c|c|c|c|}
\hline Characteristic & $\begin{array}{l}\text { Patients with } \\
\text { Acquired Rifamycin } \\
\text { Resistance }(n=8)\end{array}$ & $\begin{array}{c}\text { Patients without } \\
\text { Acquired Rifamycin } \\
\text { Resistance }(n=161)\end{array}$ & p Value \\
\hline \multicolumn{4}{|l|}{ Demographic factors } \\
\hline Median age, yr (IQR) & $38(33-42)$ & $40(34-46)$ & 0.46 \\
\hline Male/female & $7 / 1$ & $126 / 35$ & 1.00 \\
\hline \multicolumn{4}{|l|}{ Race/ethnicity, n (\%) } \\
\hline Hispanic & $5(62)$ & $52(32)$ & 0.39 \\
\hline White, non-Hispanic & $1(13)$ & $18(11)$ & \\
\hline Black & $2(25)$ & $82(51)$ & \\
\hline Native American & 0 & $3(2)$ & \\
\hline Asian/Pacific Islander & 0 & $6(4)$ & \\
\hline Born outside the United States and Canada, n (\%) & $6(75)$ & $63(39)$ & 0.06 \\
\hline Median body mass index at TB diagnosis (IQR) & $19.9(17.8-26.0)$ & $21.2(18.7-23.7)$ & 0.84 \\
\hline \multicolumn{4}{|l|}{ Aspects of TB } \\
\hline Presence of initial resistance to isoniazid or pyrazinamide, $\mathrm{n}(\%)$ & $1(13)$ & $7(4)$ & 0.33 \\
\hline \multicolumn{4}{|l|}{ Site of TB involvement, $\mathrm{n}(\%)$} \\
\hline Pulmonary only & $2(25)$ & $91(56)$ & \\
\hline Any extrapulmonary & $6(75)$ & $70(43)$ & 0.14 \\
\hline Presence of cavitation on chest radiograph, $\mathrm{n}$ (\% of those with pulmonary involvement) & $1(20)$ & $22(16)$ & 1.00 \\
\hline Bilateral lung involvement on chest radiograph, $\mathrm{n}$ (\% of those with pulmonary involvement) & $1(17)$ & $20(15)$ & 1.00 \\
\hline \multicolumn{4}{|l|}{ TB treatment } \\
\hline Use of twice-weekly therapy during intensive phase, $\mathrm{n}(\%)$ & $6(75)$ & $70(44)$ & 0.15 \\
\hline Received rifampin during intensive phase, $\mathrm{n}(\%)$ & $7(88)$ & $125(78)$ & 1.00 \\
\hline Sputum culture positive at $2 \mathrm{mo}, \mathrm{n}$ (\% of those with pulmonary involvement) & 0 & $5(4)$ & 1.00 \\
\hline Use of drugs during TB treatment that are known to decrease concentrations of rifabutin, ${ }^{*} \mathrm{n}(\%)$ & $2(25)$ & $48(30)$ & 1.00 \\
\hline Use of drugs during TB treatment that are known to increase concentrations of rifabutin, ${ }^{\dagger} \mathrm{n}(\%)$ & $3(38)$ & $72(45)$ & 1.00 \\
\hline \multicolumn{4}{|l|}{ Aspects of HIV/antiretroviral therapy } \\
\hline Median CD4 lymphocyte count at diagnosis (IQR) & $26(13-39)$ & $99(40-202)$ & 0.001 \\
\hline Median HIV RNA level at diagnosis (IQR) & $5.6(5.3-5.6)$ & $5.3(4.8-5.7)$ & 0.40 \\
\hline Use of antiretroviral therapy during TB treatment, $\mathrm{n}(\%)$ & $7(87)$ & $130(81)$ & 1.00 \\
\hline Use of antiretroviral therapy during first 2 mo of TB treatment, $\mathrm{n}(\%)$ & $1(14)$ & $73(56)$ & 0.05 \\
\hline Occurrence of an immune reconstitution event, $\mathrm{n}(\%)$ & $1(13)$ & $25(16)$ & 1.00 \\
\hline
\end{tabular}

For definition of abbreviations, see Table 1.

* Efavirenz.

${ }^{\dagger}$ HIV-1 protease inhibitors, clarithromycin, fluconazole.

${ }^{\ddagger} \mathrm{p}$ value based on Wilcoxon, $\chi^{2}$, or Fisher's exact test (see Methods).

treatment is not true for patients with advanced HIV disease. It is also notable that the drug to which resistance was acquired in this and other studies $(5,25,28,29)$ was nearly always the rifamycin component of the regimen (rifampin, rifabutin, or rifapentine). Among patients with HIV-related TB treated with directly observed therapy, there are two consistent associations in this and previous studies with the occurrence of acquired rifamycin resistance: the presence of severe immunodeficiency (CD4 lymphocyte count $<100$ cells $/ \mathrm{mm}^{3}$ ) and the use of onceor twice-weekly therapy. Acquired rifamycin resistance has been reported with twice-weekly rifabutin plus isoniazid $(4.7 \%$ in the present study) and with twice-weekly rifampin plus isoniazid
$(2.0,3.7$, and $1.7 \%)(5,29,30)$. In contrast, the rate of acquired rifamycin resistance among HIV-infected patients treated with daily $(5-7 \mathrm{~d} / \mathrm{wk})$ rifampin-based therapy $(29,31,32)$, or rifabutinbased therapy $(29,31)$ has been very low. The interpretation of these data from different clinical trials and observational cohorts is difficult. We conclude that there is a risk of acquired rifamycin resistance with rifabutin or rifampin when given twice weekly, but whether the risk is higher with one of these agents is not clear.

In addition to the associations with severity of immunosuppression and dosing frequency, abnormal pharmacokinetics of anti-TB drugs may also be a part of the pathophysiology of TABLE 3. STRATIFIED ANALYSIS OF FACTORS ASSOCIATED WITH ACQUIRED RIFAMYCIN
RESISTANCE AMONG PATIENTS WITH BASELINE CD 4 LYMPHOCYTE
COUNT $<100 \mathrm{CELLS} / \mathrm{mm}^{3}(\mathrm{n}=73)$

\begin{tabular}{|c|c|c|c|}
\hline Characteristic & $\begin{array}{l}\text { Patients with } \\
\text { Acquired Rifamycin } \\
\text { Resistance }(n=8)\end{array}$ & $\begin{array}{l}\text { Patients without } \\
\text { Acquired Rifamycin } \\
\text { Resistance }(n=65)\end{array}$ & $\mathrm{p}$ Value* \\
\hline Born outside the United States and Canada, n (\%) & $6(75)$ & $29(45)$ & 0.14 \\
\hline Any extrapulmonary site of TB involvement, $\mathrm{n}(\%)$ & $6(75)$ & $34(52)$ & 0.28 \\
\hline Use of twice-weekly therapy during intensive phase, $\mathrm{n}(\%)$ & $6(75)$ & $28(43)$ & 0.13 \\
\hline Use of antiretroviral therapy during first 2 mo of TB treatment, $\mathrm{n}(\%)$ & $1(13)$ & $32(49)$ & 0.07 \\
\hline
\end{tabular}

Definition of abbreviation: TB = tuberculosis.

* Fisher's exact test (expected values $<5$ ). 

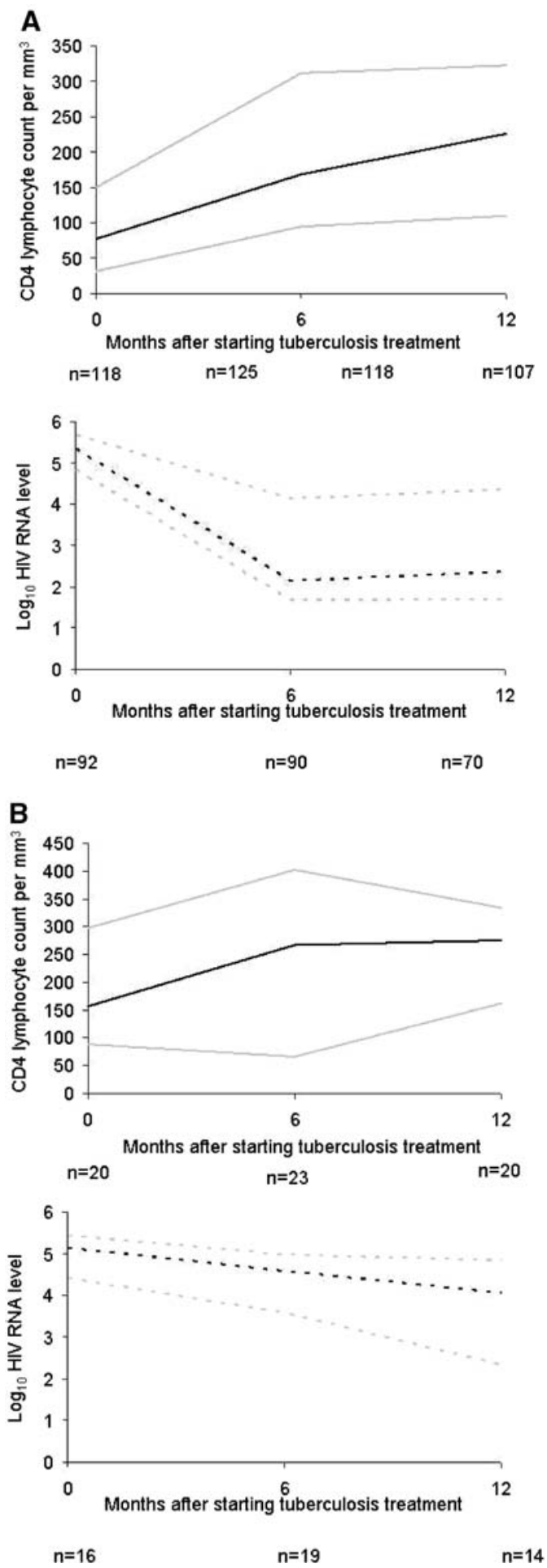

Figure 2. Changes in median HIV RNA level $\left(\log _{10}\right)$ and CD4 cell count (cells/ $\mu \mathrm{l}$ ) during the $12 \mathrm{mo}$ after the diagnosis of tuberculosis among patients who did $(A)$ and did not $(B)$ receive antiretroviral therapy during tuberculosis treatment. The median value is shown as a black line; the grey lines indicate the 25 th and 75 th percentile (the interquartile range).

acquired rifamycin resistance. Among patients in this trial who enrolled in a pharmacokinetic substudy, patients with low concentrations of rifabutin were at increased risk of acquired rifamycin resistance, even after adjusting for baseline CD4 cell count
TABLE 4. SELECTED ADVERSE EVENTS DURING TUBERCULOSIS THERAPY

\begin{tabular}{lc}
\hline Event & No. (\%) \\
\hline Serious events (Grade 4), total & $55(32.5)$ \\
Serum AST or ALT $>10$ times upper limit of normal (Grade 4) & $13(7.7)$ \\
Absolute neutrophil count $<500$ (Grade 4) & $8(4.7)$ \\
Hemoglobin & \\
$\quad<7 \mathrm{~g} / \mathrm{dl}$ (Grade 3) & $6(3.6)$ \\
$5 \mathrm{~g} / \mathrm{dl}($ Grade 4$)$ & 0 \\
Platelets $<10,000$ (Grade 4) & 0 \\
Arthralgia (any grade) & $2(1.2)$ \\
Skin rash (any grade) & $13(7.7)$ \\
Uveitis & 0 \\
Temporary discontinuation of study drugs due to toxicity & $24(14)$ \\
Permanent discontinuation of study drugs due to toxicity & $2(1)$ \\
\hline
\end{tabular}

Definition of abbreviations: ALT $=$ alanine transaminases; AST $=$ aspartate transaminase.

and dosing frequency (33). Thus, it appears that three factors are closely associated with acquired rifamycin resistance: severe immunodeficiency, highly intermittent dosing, and low concentrations of the rifamycin component of the regimen. These associations suggest that, in the relative absence of immune control, low concentrations of the rifamycin near the end of the prolonged dosing interval allow mycobacterial replication and selection for rifamycin resistance.

The risk of acquired rifamycin resistance in our study was lower among patients who received antiretroviral therapy during the first 2 mo of TB treatment. The interpretation of this finding is difficult: the study could not capture the many factors that led to differences in the timing of antiretroviral therapy, and this association has not been evaluated in previous studies. Although our sample size is relatively small, these data support the hypothesis that immune reconstitution is beneficial in the treatment of HIV-associated TB. The question of the optimal timing of antiretroviral therapy during TB treatment is complex and is currently being evaluated in randomized clinical trials.

The TB treatment regimen in this study was chosen to determine if TB treatment could be used safely with potent antiretroviral therapy. In that respect, the study regimen succeeded; most patients received and benefited from potent antiretroviral therapy during TB therapy. Baseline characteristics of patients in this trial were quite similar to those of patients enrolled in a trial that was performed in many of the same study sites, before the availability of potent antiretroviral therapy (Table 5). The markedly lower rates of death (4.9 vs. $20.0 \%$ ) and new opportunistic illness during the first year after TB diagnosis in the present study suggest that the benefits of antiretroviral therapy can be extended to patients being treated for TB. This is an important finding because TB is the most common opportunistic infection in areas of the world with high rates of HIV infection, areas in which combination antiretroviral therapy is now being introduced. Rifabutin has only been approved in a relatively small number of resource-rich countries (e.g., United States and western Europe). This limits the direct application of our results to many countries with high rates of HIV-related TB in which rifampin is the only available rifamycin antibiotic. However, some potent antiretroviral regimens (e.g., efavirenz or ritonavir with two nucleoside analogs) can be used with rifampin-based TB therapy $(11,34)$, and should allow patients to obtain the benefits of potent antiretroviral therapy given during TB treatment.

The major limitation of this study is the lack of a randomized comparison group. Although use of twice-weekly therapy was associated with acquired rifamycin resistance among patients 
TABLE 5. COMPARISON OF USE OF COMBINATION ANTIRETROVIRAL THERAPY AND RATES OF HIV DISEASE PROGRESSION IN A TREATMENT OF HIV-RELATED TUBERCULOSIS IN THE UNITED STATES AND CANADA IN THE ERA PRIOR TO POTENT ANTIRETROVIRAL THERAPY VERSUS THE PRESENT STUDY

\begin{tabular}{lcc}
\hline & $\begin{array}{c}\text { CPCRA/ACTG* } \\
(n=101)\end{array}$ & $\begin{array}{c}\text { Present Study } \\
(n=169)\end{array}$ \\
\hline Years of enrollment & $1993-1995$ & $1999-2002$ \\
Median enrollment CD4 cell count (IQR) & $86(35-230)$ & $90(35-175)$ \\
Use of potent antiretroviral therapy during TB treatment, $n$ (\%) & 0 & $137(81)$ \\
Death within 12 mo of starting TB treatment (\% by Kaplan-Meier analysis) & 20.0 & 4.9 \\
HIV disease progression (new opportunistic infection or death) within & 38.9 & 15.4 \\
12 mo of starting TB treatment (\% by Kaplan-Meier analysis) & 3.9 \\
\hline
\end{tabular}

Definition of abbreviations: $\mathrm{ACTC}=$ AIDS Clinical Trials Group; CPCRA $=$ Community Programs for Clinical Research on AIDS; $\mathrm{IQR}=$ interquartile range; $\mathrm{TB}=$ tuberculosis.

* Data from Reference 5.

with low baseline CD4 lymphocyte counts, our study did not include a group randomized to more frequent dosing. Evaluating the relationship between dosing frequency and the success of treatment of HIV-related TB should be a high priority for future randomized studies. Although this is one of the largest prospective studies of treatment of HIV-related TB, the sample size limits the power of subgroup comparisons. Finally, the substantial proportion of patients lost after the first year of follow-up, but before completing $2 \mathrm{yr}$ of follow-up, is a limitation of our study.

A largely twice-weekly rifabutin-based regimen for HIVrelated TB was associated with an unacceptable risk of acquired rifamycin resistance. The results of this and other studies were the basis for national recommendations that persons with CD4 lymphocyte counts of less than 100 cells $/ \mathrm{mm}^{3}$ should not be treated with twice-weekly therapy, at least during the first 2 mo of therapy $(18,35)$. Patients with baseline CD4 lymphocyte counts more than 100 cells $/ \mathrm{mm}^{3}$ did well in this study, but additional experience is needed to evaluate intermittent therapy in this important subgroup. Intermittent therapy greatly facilitates directly observed therapy, so randomized trials of dosing frequency should be a high priority among patients with HIVrelated TB. Finally, our study supports the recommendation to use antiretroviral therapy among patients with advanced HIV disease and TB (16), as such patients can obtain dramatic benefits from potent antiretroviral therapy.

Conflict of Interest Statement: W.B. does not have a financial relationship with a commercial entity that has an interest in the subject matter of this manuscript. D.B. does not have a financial relationship with a commercial entity that has an interest in the subject matter of this manuscript. A.V. does not have a financial relationship with a commercial entity that has an interest in the subject matter of this manuscript. A.K. does not have a financial relationship with a commercial entity that has an interest in the subject matter of this manuscript. B.J. does not have a financial relationship with a commercial entity that has an interest in the subject matter of this manuscript. C.S. does not have a financial relationship with a commercial entity that has an interest in the subject matter of this manuscript. C.L. is employed by Glead Sciences, Inc., since August 2004, and owns 200 shares of Glead Common Stock in an employee stock purchase plan. S.W. does not have a financial relationship with a commercial entity that has an interest in the subject matter of this manuscript. B.K. does not have a financial relationship with a commercial entity that has an interest in the subject matter of this manuscript. B.M. does not have a financial relationship with a commercial entity that has an interest in the subject matter of this manuscript. M.W. does not have a financial relationship with a commercial entity that has an interest in the subject matter of this manuscript. W.E.-S. does not have a financial relationship with a commercial entity that has an interest in the subject matter of this manuscript.

Acknowledgment: The authors thank the many patients who contributed to the success of this trial. They also thank Drs. Kenneth Castro, Rick O'Brien, and M. Elsa Villarino for continued support within CDC, and local TB program staff, who assisted in the clinical management of the participants. Bayer Corporation provided test kits (Versant HIV-1 RNA 3.0 assay [bDNA]) for the HIV viral load assessments.
Participating clinical sites (principal investigators and study coordinators, with numbers of patients enrolled in brackets) were as follows: Los Angeles County/ University of Southern California Medical Center (Brenda Jones, M.D., Claudia Silva, R.N. [29]); University of North Texas Health Science Center (Stephen Weis, D.O., Barbara King, R.N., Norma Shaffer, L.V.N. [15]); Houston VA Medical Center (Christopher Lahart, M.D., Ruby Nickson, R.N., Terry Scott, R.N., Robert Awe, M.D. [14]); Audie L. Murphy VA Hospital, San Antonio (Marc Weiner, M.D., Melissa Engle, R.N. [13]); Johns Hopkins University School of Medicine (Richard Chaisson, M.D., Tim Sterling, M.D., Kristina Moore, R.N., Judith Hackman, R.N. [13]); Carolinas Medical Center (James Horton, M.D., Beth Quinn, R.N. [12]); Nashville VA Medical Center (Douglas Kernodle, M.D., Anthony Chapdelaine, M.D., Guat-Siew McKee, M.D., Linda Reeves-Hammock, R.N. [11]); New lersey Medical School National TB Center-University of Medicine and Dentistry of New Jersey (Lee B. Reichman, M.D., M.P.H., Bonita T. Mangura, M.D., Marilyn Owens, R.N., Cora Leus, R.N. [8]); Bellevue Hospital Center, New York University (Neil Schluger, M.D., William Rom, M.D., Rany Condos, M.D., Laurie Sandman, R.N. [7]); University of California at San Francisco Medical Center (Charles Daley, M.D., Llewellyn Stanton, R.N. [7]); University of British Columbia Health Center (Mark Fitzgerald, M.B., Eduardo Hernandez, M.D., Banafsheh Peyvandi, M.D. [7]); Harlem Hospital Center (Wafaa El-Sadr, M.D., Frantz Medard, M.D., Mary Klein, R.N. [6]); Denver Health and Hospitals (Randall Reves, M.D., William Burman, M.D., Jan Tapy, R.N. [5]); Chicago VA Medical Center-Lakeside (Mondira Bhattacharya, M.D., Julie Fabre, R.N. [5]); University of Manitoba (Earl Hershfield, M.D., Gerry Izon, R.N. [4]); Columbia University College of Physicians and Surgeons and the New York City Department of Health (Neil Schluger, M.D., Joseph Burzinski, M.D., Sonal Munsiff, M.D., Vilma Lozano, R.N. [4]); Hines VA Medical Center and Suburban Cook County TB District, Illinois (Constance Pachuki, M.D., Mary Samuel, R.N., James Gallai, M.D. [3]); Seattle King County Health Department (Charles Nolan, M.D., Stefan Goldberg, M.D., Marcia Stone, R.N., Debra Schwartz, R.N. [2]); VA Medical Center-Washington DC (Fred Gordin, M.D., Debra Benator, M.D., Donna Sepulveda Conwell, R.N., Thomas Walsh, M.D., Margaret Lankford, R.N., Charlotte Quinlan-Mauzy, R.N. [2]); and Duke University Medical Center and Durham VA Medical Center (Carol Dukes Hamilton, M.D., Ann Mosher, R.N. [2]).

Trial administration and data management were performed at CDC by Sharlene Broadnax, Crystal Carter, Kenneth Dansbury, Melissa Fagley, Lon Gross, Constance Henderson, Margaret Jackson, Tashawnya Rainey. Microbiologic data collection was supervised by Lorna Bozeman, M.S. CDC laboratory testing was performed or supervised by Robert Cooksey, Ph.D., Jack Crawford, Ph.D., Lois Diem, Beverly Metchock, Dr.P.H., Glenn Morlock, David Sikes, Lauren Steinlein, David Temporado, and Sean Toney. Data and safety monitoring were performed by Harold Jaffe, M.D., James Neaton, Ph.D., and John Bass, M.D.

\section{References}

1. Corbett EL, Churchyard GJ, Charalambos S, Samb B, Moloi V, Clayton TC, Grant AD, Murray J, Hayes RJ, De Cock KM. Morbidity and mortality in South African gold miners: impact of untreated disease due to human immunodeficiency virus. Clin Infect Dis 2002;34:12511258.

2. Blaxhult A, Kirk O, Pedersen C, Dietrich M, Barton SE, Gatell JM Mulcahy F, Hirschel B, Mocroft A, Lundgren JD. Regional differences in presentation of AIDS in Europe. Epidemiol Infect 2000;125:143-151.

3. Sircar AR, Tripathi AK, Choudhary SK, Misra R. Clinical profile of AIDS: a study at a referral hospital. J Assoc Physicians India 1998;46: 775-778.

4. Small PM, Schecter GF, Goodman PC, Sande MA, Chaisson RE, Hopewell PC. Treatment of tuberculosis in patients with advanced human immunodeficiency virus infection. N Engl J Med 1991;324:289294. 
5. El-Sadr W, Perlman DC, Matts JP, Nelson ET, Cohn DL, Salomon N, Olibrice M, Medard F, Chirgwin KD, Mildvan D, et al. Evaluation of an intensive intermittent-induction regimen and short course duration of treatment for HIV-related pulmonary tuberculosis. Clin Infect Dis 1998;26:1148-1158.

6. Kassim S, Sassan-Morokro M, Ackah A, Abouya LY, Digbeu H, Yesso G, Coulibaly IM, Coulibaly D, Whitaker PJ, Doorly R, et al. Two-year follow-up of persons with HIV-1- and HIV-2-associated pulmonary tuberculosis treated with short-course chemotherapy in West Africa. AIDS 1995;9:1185-1191.

7. Palella F Jr, Delany K, Moorman A, Loveless M, Fuhrer J, Satten G, Aschman D, Holmberg S, HIV Outpatient Study (HOPS) Group. Declining morbidity and mortality among patients with advanced human immunodeficiency virus infection. N Engl J Med 1998;338:853860.

8. Mocroft A, Vella S, Benfield TL, Chiesi A, Miller V, Gargalianos P, d'Arminio Monforte A, Yust I, Bruun JN, Phillips AN, et al. Changing patterns of mortality across Europe in patients infected with HIV-1. EuroSIDA Study Group. Lancet 1998;352:1725-1730.

9. Dean GL, Edwards SG, Ives NJ, Matthews G, Fox EF, Navaratne L, Fisher M, Taylor GP, Miller R, Taylor CB, et al. Treatment of tuberculosis in HIV-infected persons in the era of highly active antiretroviral therapy. AIDS 2002;16:75-83.

10. Burman WJ, Jones BE. Treatment of HIV-related tuberculosis in the era of effective antiretroviral therapy. Am J Respir Crit Care Med 2001:164:7-12.

11. Moreno S, Podzamczer D, Blazquez R, Iribarren JA, Ferrer E, Reparaz J, Pena JM, Cabrero E, Usan L. Treatment of tuberculosis in HIVinfected patients: safety and antiretroviral efficacy of the concomitant use of ritonavir and rifampin. AIDS 2001;15:1185-1187.

12. Burman WJ, Gallicano K, Peloquin C. Therapeutic implications of drug interactions in the treatment of HIV-related tuberculosis. Clin Infect Dis 1999;28:419-430.

13. Gonzalez-Montaner LJ, Natal S, Yonchaiyud P, Olliaro P. Rifabutin for the treatment of newly-diagnosed pulmonary tuberculosis: a multinational, randomized, comparative study versus rifampicin. Tuber Lung Dis 1994;75:341-347.

14. McGregor MM, Olliaro P, Wolmarans L, Mabuza B, Bredell M, Felten MK, Fourie PB. Efficacy and safety of rifabutin in the treatment of patients with newly diagnosed pulmonary tuberculosis. Am J Respir Crit Care Med 1996;154:1462-1467.

15. Schwander S, Rusch-Gerdes S, Mateega A, Lutalo T, Tugume S, Kityo C, Rubaramira R, Mugyenyi P, Okwera A, Mugerwa R, et al. A pilot study of antituberculosis combinations comparing rifabutin with rifampicin in the treatment of HIV-1 associated tuberculosis: a single-blind randomized evaluation in Ugandan patients with HIV-1 infection and pulmonary tuberculosis. Tuber Lung Dis 1995;76:210-218.

16. Centers for Disease Control and Prevention. Prevention and treatment of tuberculosis among patients infected with human immunodeficiency virus: principles of therapy and revised recommendations. MMWR Morb Mortal Wkly Rep 1998;47(RR-20):1-58.

17. Burman W, Benator D, Vernon A, Khan A, El-Sadr W, Silva C, Lahart C, Weis S, Mangura B, King B, et al. Use of antiretroviral therapy during treatment of active tuberculosis with a rifabutin-based regimen [abstract 106]. Tenth Conference on Retroviruses and Opportunistic Infections. Boston, MA: Foundation for Retrovirology and Human Health; 2003.

18. Centers for Disease Control and Prevention. Acquired rifamycin resistance in persons with advanced HIV disease being treated for active tuberculosis with intermittent rifamycin-based regimens. MMWR Morb Mortal Wkly Rep 2002;51:214-215.

19. Centers for Disease Control and Prevention. Updated guidelines for the use of rifabutin or rifampin for the treatment and prevention of tuberculosis among HIV-infected patients taking protease inhibitors or nonnucleoside reverse transcriptase inhibitors. MMWR Morb Mortal Wkly Rep 2000;49:185-189.

20. Cave MD, Eisenach KD, Templeton G, Salfinger M, Mazurek G, Bates JH, Crawford JT. Stability of DNA fingerprint pattern produced with IS6110 in strains of Mycobacterium tuberculosis. J Clin Microbiol 1994;32:262-266.

21. Kwara A, Schiro R, Cowan LS, Hyslop NE, Wiser MF, Roahen Harrison S, Kissinger P, Diem L, Crawford JT. Evaluation of the epidemiologic utility of secondary typing methods for differentiation of Mycobacterium tuberculosis isolates. J Clin Microbiol 2003;41:2683-2685.

22. Miller LP, Crawford JT, Shinnick TM. The rpoB gene of Mycobacterium tuberculosis. Antimicrob Agents Chemother 1994;38:805-811.

23. Harrell F. Regression modeling strategies for improved prognostic prediction. Stat Med 1984;3:143-152.

24. Centers for Disease Control and Prevention. Tuberculosis control among homeless populatioins. JAMA 1987;257:2886-2888.

25. Sterling TR, Alwood K, Gachuhi R, Coggin W, Blazes D, Bishai WR, Chaisson RE. Relapse rates after short-course (6-month) treatment of tuberculosis in HIV-infected and uninfected persons. AIDS 1999; 13:1899-1904.

26. Weis SE, Slocum PC, Blais FX, King B, Nunn M, Matney GB, Gomez E, Foresman BH. The effect of directly observed therapy on the rates of drug resistance and relapse in tuberculosis. N Engl J Med 1994; 330:1179-1184.

27. Hong Kong Chest Service/British Medical Research Council. Controlled trial of 6-month and 8-month regimens in the treatment of pulmonary tuberculosis: the results up to 24 months. Tubercle 1979;60:201-210.

28. Vernon A, Burman W, Benator D, Khan A, Bozeman L. Relapse with rifamycin mono-resistant tuberculosis in HIV-infected patients treated with supervised once-weekly rifapentine and isoniazid. Lancet 1999; 353:1843-1847.

29. Li J, Munsiff SS, Driver CR, Sackoff J. Relapse and acquired rifampin resistance in HIV-infected patients with tuberculosis treated with rifampin-, or rifabutin-based regimens in New York City, 1997-2000. Clin Infect Dis 2005;41:83-91.

30. Nettles RE, Mazo D, Alwood K, Gachuhi R, Maltas G, Wendel K, Cronin W, Hooper N, Bishai W, Sterling TR. Risk factors for relapse and acquired rifamycin resistance after directly observed tuberculosis treatment: a comparison by HIV serostatus and rifamycin use. Clin Infect Dis 2004;38:731-736.

31. Hung CC, Lee HC, Hseih SM, Sheng WH, Ko WC, Hsaio CF, Liu WC, Chen MY. Effectiveness of highly active antiretroviral therapy and antituberculous therapy combinations for HIV-infected patients with active tuberculosis. Eleventh Conference on Retroviruses and Opportunistic Infections. San Francisco, CA: Foundation for Human Retrovirology; 2004.

32. Sonnenberg P, Murray J, Glynn JR, Shearer S, Kambashi B, GodfreyFaussett P. HIV-1 and recurrence, relapse, and reinfection of tuberculosis after cure: a cohort study in South African mineworkers. Lancet 2001;358:1687-1693.

33. Weiner M, Benator D, Burman W, Peloquin C, Khan A, Vernon A, Jones B, Silva-Trigo C, Zhao Z, Hodge T, et al. The association between acquired rifamycin resistance and the pharmacokinetics of rifabutin and isoniazid among patients with tuberculosis and HIV. Clin Infect Dis 2005;40:1481-1491.

34. Lopez-Cortes LF, Ruiz-Valderas R, Viciana P, Alarcon-Gonzalez A, Gomez-Mateos J, Leon-Jimenez E, Sarasanacenta M, Lopez-Pua Y, Pachon J. Pharmacokinetic interactions between efavirenz and rifampicin in HIV-infected patients with tuberculosis. Clin Pharmacokinet 2002;41:681-690.

35. Blumberg HM, Burman WJ, Chaisson RE, Daley CL, Etkind SC, Friedman LN, Fujiwara P, Grzemska M, Hopewell PC, Iseman MD, et al. American Thoracic Society/Centers for Disease Control and Prevention/Infectious Diseases Society of America: treatment of tuberculosis. Am J Respir Crit Care Med 2003;167:603-662. 